\title{
Student's Response and Behavior in the Classroom Environment
}

\author{
${ }^{1}$ Deepa Joshi, ${ }^{2}$ Vasudha A. Gokhale, ${ }^{1}$ Anjali Acharya \\ ${ }^{1}$ University of Bhopal, University of Pune
}

\begin{abstract}
Problematic behavior of students in the classroom causes destruction to the learning environment, teacher's concentration and adversely affects social and educational level of the student. Present paper put forth the various reasons responsible for behavioral problems in school classrooms. Based on an in depth study of secondary schools at Pune, India, it analyses the various approaches that are adopted by teachers and the respective effect on student's behavior and performance in classroom to overcome this problem . This is aimed to suggest new approaches which go beyond explicitly academic interventions to take on the learning challenges posed by problematic student behavior and the ways schools deal with it. It endeavors to put forth measures considering that the social and behavioral environment of a classroom can reflect the overall academic environment of the school broadly, and stress on the contributions of strategies or programs to improving student behavior by and large.
\end{abstract}

\section{Introduction}

Education system is rapidly changing in Indian schools where much of the attention currently given to improving students' academic achievement addresses issues of curriculum, instructional strategies, and interventions or services for students. However, even after addressing these issues, barriers still remain for some students. Approaches aimed at improving school and classroom environments, including reducing the negative effects of disruptive or distracting behaviors, can enhance the chances that effective teaching and learning will occur, both for the students exhibiting problem behaviors and for their classmates. An estimated one-third of students fail to learn because of psychosocial problems that interfere with their ability to fully attend to and engage in instructional activities, prompting a call for new directions for addressing barriers to learning. Pune is called "Oxford of the East" is now facing the problem of unusual behavior of the school students at large scale. Increased academic pressure in addition to lots of exposure to audio-visual media has changed the mind set of secondary students alarmingly causing behavioral problems.

Schooling is an intrinsically social enterprise. Student behavior is shaped by and exhibited and interpreted in a social context that involves multiple actors viz. teachers, students, school staff etc. It includes multiple settings like classrooms, corridors, common areas, laboratories, lunch room, and playground. Schools are institutions with multiple goals like enhancing academic performance, encouraging a holistic development of the student. Positive behavior is more likely to thrive when relationships at all levels are trusting and supportive and reflect a shared commitment to establish a healthy school and community. Problem behavior of students not only interrupts teacher's lesson plans but also disturbs other student's learning process. Such students test teacher's patience as a result many feeling overwhelmed, helpless and make teaching as one of the most difficult aspects of a teacher's job. The most common problem behaviors in the classroom teachers notice are a student's lack of focus, and the inability to sit/stand for an appropriate length of time required for effectively learning.

Student's behavior reflects the interaction of their temperament and inherited personality, the history of their experiences, and the particular nature of each situation. In most circumstances it is impossible to determine what proportion each of these elements contributes to a given manifestation. It also differ in proportions which vary from student to student and even from situation to situation for a single student. Although it is difficult to modify personality of a student having problem behavior, it is possible to modify behavior by identifying and correcting adverse situations in the environment and by introducing appropriate interventions. If adverse environmental conditions are corrected at an early stage, there is a greater possibility of preventing or diminishing their impact on behavioral pattern of student in question [1].

\section{Problem Behavior}

Behavioral disorders also known as conduct disorders are one of the most common forms of psycho pathology among children and young adults and is the most frequently cited reason for referral to mental health services in schools. The appearance of behavioral disorders is increasing dramatically in Pune's secondary school classrooms in last decade. As a result their presence severely constrains the ability of the school systems to educate students effectively. The prevalence of behavioral problems among children and young adults is substantial. 
Surveys indicate that behavioral disorders vary among young adults, ranging from 2 and $6 \%$ in secondary school students.

Behavioral disorders become apparent when the student displays a repetitive and impact persistent pattern of behavior that results in the significant disruption in other students. Such disturbances may cause significant impairments in academic, social, and or occupational functioning. Such a behavior pattern is consistent throughout the individual's life. Among the characteristics of a behavioral disorder among students of secondary schools are:

- Initiation of aggressive behavior and reacting aggressively towards others.

- A display of bullying, threatening, or intimidating behavior.

- Being physically abusive of others.

- Deliberate destruction of other's belongings and property.

- Showing little empathy and concern for the feelings, wishes, and well being of classmates.

- Showing callous behavior towards others and lack of feelings of guilt or remorse.

- They may readily inform on their companions and tend to blame others for their own misdeeds.

\section{Behavior as a phenomenon}

The notion that behavior is learned student's behaviors are shaped by the expectations and examples provided by important adults like parents and teachers in their lives and by their peers. In the elementary to secondary grades, general education classroom teachers are arguably the most important adults at school for the large majority of students. As such, they can play a critical role both in proactively teaching and reinforcing appropriate student behaviors and in reducing the frequency of behaviors that impede learning. Accepting responsibility for the behavioral learning of all students is a natural extension of the responsibility for the academic learning of all students that general education teachers exercise with such purpose every day. Factors affecting Student's behavior include socioeconomic status, number of students in the grade, gender, parental education, type of school attended and academic ability.

A combination of nature and nurture may make some students more likely to develop behavioral problems. Young children who had both a stressful home life and an exaggerated nervous system response to stress were more likely than their peers to develop behavioral problems over the next six years. In the case of students who are surrounded by stressful conditions and have a stronger physiological response to stress, the combination may set them on a course toward an "under controlled" personality. Students of secondary schools students with this personality type have difficulty adapting their behavior to different circumstances, tend to be plagued by negative emotions, and often have behavioral problems such as fighting with their classmates. Some of the behavioral indices as identified are as below:

- Losing one's temper

- Arguing with adults

- Actively defying requests

- Refusing to follow rules

- Deliberately annoying other people

- Blaming others for one's own mistakes or misbehavior

- Being touchy easily annoyed or angered, resentful, spiteful, or vindictive.

Objectionable behavior is usually diagnosed when a student has a persistent or consistent pattern of disobedience and hostility toward parents, teachers, or other adults. The primary behavioral difficulty is the consistent pattern of refusing to follow commands or requests by adults. Students with objectionable behavior often are stubborn test limits and push boundaries and they easily become annoyed. The criteria for objectionable behavior are met only when the problem behaviors occur more frequently in the student than in other students of the same age and developmental level. These behaviors cause significant difficulties with family and friends, and the oppositional behaviors are the same both at home and in school. Sometimes, objectionable behavior may be a precursor of a conduct disorder [15]. Risk factors for students of secondary standard who are teenager's behavior problems include:

- Family conflict

- Academic failure in elementary school

- Friends who engage in alcohol and drug use, delinquent behavior, violence, or other problem behaviors

- Peer rejection

- Family history of a problem behavior

- Favorable parental attitudes to problem behavior

- Witnessing family violence

Family instability, including economic stress, parental mental illness, harshly punitive behaviors, inconsistent parenting practices, multiple moves, and divorce may also contribute to the development of oppositional and defiant behaviors [17].

\subsection{Sensory processing disorder}

Students generally tend to avoid or appear fearful of particular activities like playground equipment, certain sounds messy play, movement experiences, smells, or tastes. They seemed to be uncoordinated 
and react in an undesirable manner like crashing and banging into or on objects, sometimes accidentally breaking objects nearby. They generally have difficulty with social interactions and relating to their peers. These problem behaviors in the classroom exhaust children and teachers both. Such students need some additional help on a daily basis.

Students display a wide range of behavior problems in classrooms ranging from disruptive talking in the classroom to fighting and name-calling on the playground because of simple reasons. Problem behavior will depend upon an individual teacher's tolerance. Classroom behavior is one of the trickiest issues teachers face today as it creates a classroom environment that is not conducive to learning. In order to overcome behavioral problems is to promote positive behavior before problems arise. Disruptive classroom behavior needs to be explored because it could signal that something more is going on than meets the eye. There are many conflicting theories about how to manage classroom behavioral problems like logical consequences, behavior management and assertive discipline etc.

\subsection{Avoidance Behaviors}

Student's self acceptance largely depends on their competitive performance. Students who are not able to fulfill the academic requirements because of a number of reasons are not necessarily capable of doing so but this is normally considered as the evidence of their inability and is reason to despair. They are uncertain about their ability to face challenges and competition and they generally follow strategies that deflect attention from their activities in order to protect self-worth. As per Covington these are "ruses and artful dodges" that are used as ploys in "the struggle to escape being labeled as stupid. In addition students start avoiding seeking help, resisting novel approaches to academic work, and purposefully withdrawing effort which is a sort of self-handicapping. While contemplating seeking help they are scared of to be criticized and perceive a threat to self-worth from not only from teachers but also from their classmates. Some students have a passive attitude and they prefer to avoid to attempt of solving problems and doing their work because they feel that they may make mistakes and demonstrate their low ability. In this way they succeeded to stave off the chance of to be exposed as incapable but this strategy to avoid undermine their performance.

Students show aggressive, withdrawn, and inattentive-hyperactive behaviors because of peer rejection. Acceptance by peers depends on student's behavior and rejection results from deficits in student's social skills. Aggressive students show deregulated behaviors, they are inattentive, reactive and disruptive. Because of their unskilled behaviors along with their aggression, they are at high risk for peer rejection. Their inattentive and hyperactive behaviors impair their ability to interact effectively with peers. Aggressive behavior is adopted for self protection proved instrumental for goal attainment. Aggressive students also establish and maintain friendship and are not always rejected by peers, while students with inattentive and hyperactive behaviors results in peer rejection.

\subsection{Motivation}

Psychological research has pointing out that dominant perspectives are "varieties of cognitive approaches to motivation. They focused on attributions, perceived ability, perceived control and competence, intrinsic motivation, interest, learning strategies, and goal orientations. In educational research focus is on the teacher behaviors which are capable of promoting student motivation. Students can be motivated with the help of different teacher behaviors such as guidance, modeling, enthusiasm, provision of choice, sincere praise, reinforcement, and curiosity, dissonance, and interest-induction. four basic strategies are viz. attention focusing, relevance, confidence building, and satisfaction. Both the disciplines psychology and education provide complementary perspectives on the links between teacher behavior and student motivation. Motivation is largely influenced by student engagement in the classroom and relevant dimensions of teacher behavior. Motivation represents the intensity and emotional quality of student's involvement in initiating and carrying out learning activities where engagement includes both behavioral and emotional components.

\section{The Class Room Response}

It is observed that certain classroom discourse practices proved supportive as far as student's behavior in classroom is concerned. It includes instruction, motivation, and organizing classroom time and activities. In majority of schools surveyed general education classrooms are generally orderly, teacher-student and student-student relationships are positive, and teaching and learning go on without major disruption. Teachers in such classrooms recognize the importance of preventing significant behavior problems and are effectively using fundamental prevention tools, engaging instruction, well-managed classrooms, and positive relationships with students. Looking to these prevention fundamentals should always be the first step in promoting good behavior at school. However, it has been noticed that some teachers have a class in which one or a few student's exhibit persistent or significant problem behaviors, those that are 
disruptive, oppositional, distracting, or defiant. Sometimes when a number of students in a classroom demonstrate such behaviors, it can create a chaotic environment that is a serious impediment to learning for all students. In these cases teachers have exhausted their classroom management strategies without successfully eliminating the obstacles to learning that problem behaviors pose.

\subsection{Student's Behavior in Classrooms}

To understand the very cause of behavioral problems, it is important to study specific behavior a student exhibits, its effects on learning, and when, where, and how often it occurs [16]. This information can provide important clues to the underlying purpose of the problem behavior and a foundation for developing effective approaches to mitigate it. Many times classroom conditions or activities if changed or modified can influence the frequency or intensity of problem behaviors. If the teacher understands the behavioral hot spots in the classroom in terms of timing, setting, and instructional activities, they can proactively develop class wide and individual student strategies. It is evident that a change in instructional groupings, the seating plan, or the order or pace of reading proved instrumental to reduce the contribution of these classroom factors to students' problem behaviors.

In many cases students' failure to meet behavioral expectations reflects deficits in specific social or behavioral skills. In such a case explicit instruction can help students overcome some academic deficits in addition to this it can help students learn the positive behaviors and skills they are expected to exhibit at school. It has been observed that it is very difficult for a teacher at one time or another to remedy an individual student's behavior problem that is not responsive to preventative efforts. The success of a behavioral intervention hinges on identifying the specific conditions that prompt and reinforce the problem behavior. For this it is necessary to analyze the behavior's antecedents and consequences. It can be done by careful observation of the conditions in which the problem behavior is likely to occur and not occur. This information can be used to tailor effective and efficient intervention strategies that respond to the needs of the individual student within the classroom context.

\subsection{Role of School}

There are many factors within the schools that contribute to antisocial behavior. Anti social behavior of student may be because of setting events which are defined as antecedents that precede the antisocial behavior and occur within the same setting and affect subsequent stimulus-response relations.
Many times a series of instructions followed by several errors act as a setting event for the next instruction which result problem behavior such as aggression.

School staff has to play a crucial role to solve behavioral problem in classrooms [2]. If the staff provides adequate guidance to the students regarding how they can use appropriate behaviors to replace problem behaviors. Provision of positive reinforcement consistently when student do so can increase students' chances of experiencing social and behavioral success. It can be done by the collective wisdom and the success depends on problem-solving abilities of school staff. Teachers should be encouraged to reach out to colleagues in the school, other classroom teachers, special educators, the school psychologist, or administrators to help meet the behavioral needs of their students.

\section{Functional Behavioral Assessment}

Functional behavioral assessment is an approach that incorporates a variety of techniques and strategies to diagnose the causes and to identify likely interventions intended to address problem behaviors. It looks beyond the overt topography of the behavior, and focuses, instead, upon identifying biological, social, affective, and environmental factors that initiate, sustain, or end the behavior in question. This approach is important because it leads the observer beyond the symptom or the behavior to the student's underlying motivation to escape, avoid, or get something which is, to the functional analyst, the root of all behavior. The behavior intervention plans stemming from the knowledge of why a student misbehaves based on a functional behavioral assessment are extremely useful in addressing a wide range of problems [12]. The function of behavior is to modify the classroom learning environment to decrease problem behavior. Many effective classroom-focused interventions to decrease students' problematic behavior alter or remove factors that trigger them. These triggers can result from a mismatch between the classroom setting or academic demands and a student's strengths, preferences, or skills. Teachers can reduce the occurrence of inappropriate behavior by revisiting and reinforcing classroom behavioral expectations; rearranging the classroom environment, schedule, or learning activities to meet students' needs; and/or individually adapting instruction to promote high rates of student engagement and on-task behavior [13].

\section{School Education in Pune}

About 38,476 children between 6 and 14 years are seeking admission to schools across Pune district. School education in Pune begins from the 
primary level. Primary schools in Pune are either run by the Pune Municipal Corporation (PMC) or privately by Trusts and individuals. The schools in Pune are broadly categorized into Public schools and private schools. Majority of the people in the city prefer private schools, due to their modern infrastructural facilities and good quality of education.

\subsection{Methods}

A qualitative cross sectional study was conducted in 2 selected schools in Pune among 4 age groups of children, studying in different standards from Junior $\mathrm{KG}$ to $\mathrm{Xth}$. Focus groups and interviews with randomly selected children were conducted. The sample was worked out from total 1525 students studying in 35 sections of class $\mathrm{V}$ to $\mathrm{X}$ in the two schools, by a two stage random sampling technique. In the first stage, lots have been drawn, from each of the six classes one section was selected to be included in the study. In the second stage, the students from the selected six sections, which worked out to 450 were examined thoroughly

\subsection{Diagnostic analysis of situations that foster disruptive behavior in students}

A sample of 450 secondary school children, aged 4-14 yrs. in Pune, was evaluated with the help of questionnaire survey with reference to student behavior. The frequency of behavior problems in classrooms of secondary schools was $6.8 \%-8.2 \%$ antisocial behavior while $0.78 \%$ neurotic behavior.

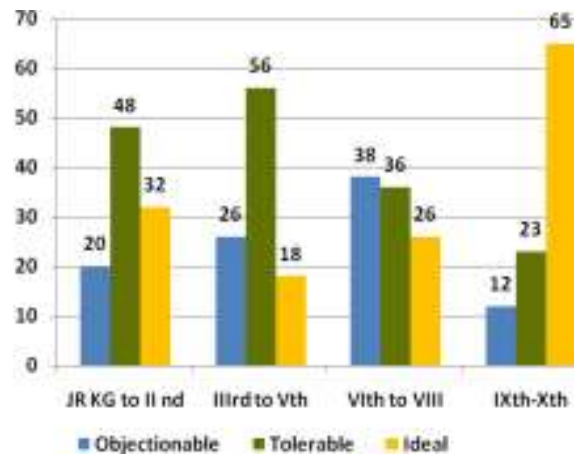

Figire 1. Student's Behavior Pattern

Objectionable behavior was noticed predominantly noticed in students studying is standard VI th to VIII, which is observed least at higher level as students became more mature and serious about studies. Objectionable behavior at lower level is found to be because of adjustment problems [14]. Students of standard III rd to VIII ${ }^{\text {th }}$ were found to be stubborn and difficult to handle (see Figure 1).
Student's performance and behavior in classroom depends on the subject taught and teaching, instruction method adopted by the teacher (see Figure 2). In mathematics class majority of students show reluctance and problem behavior as it is a comparatively difficult subject to learn. In science a large number of student's have behavioral problem as they are not finding the subject interesting if it is taught as a theoretical based method and in the absence of experiments. A mixed response was observed for geography subject where students showed reluctance as well as cause disturbance to others. In language classes like English and Marathi which is one of the native language most of the student found interactive and participating in the classroom activities at the same time many of them had objectionable behavior as they did not have aptitude for the subject and they found instruction method tedious and boring.

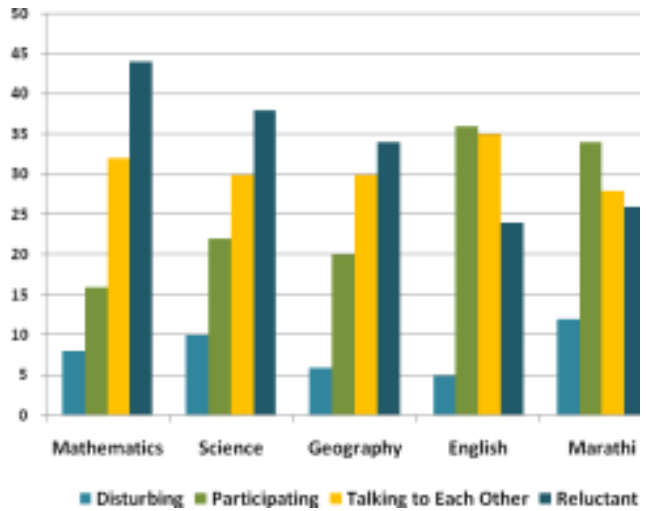

Figure 2. Students Behavior with reference to subject taught

Student's relationship to the teacher is a matter of concern which largely depend on teacher's attitude and way how they handle students [6]. Many teachers are found to be very strict; many are lenient while many adopt a balanced friendly behavior in class [7]. Less behavioral problems noticed in class of teachers who prefer to be friendly with students as compared to strict or lenient teachers (see Figure 3).

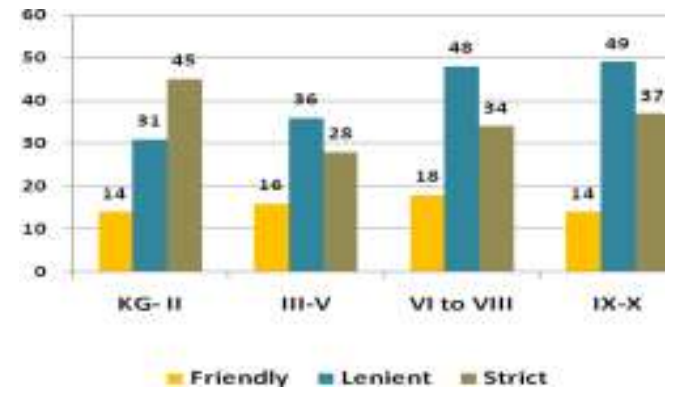

Figure 3. Effect of Teacher's Personality

Student's relationship with teacher also has an influence with the age of teacher [5]. Students 
studying at lower standards like in junior or senior KG prefer either young teacher because they are more comfortable with them or elder ones (Figure 4 is showing preference of students studying in various standards based on age group). Behavior problems were found higher in boys than girls. Antisocial behavior was dominant in boys, while neurotic behavior was common in girls. The frequency of behavior problems varied significantly with the different social environments in which the children were brought up

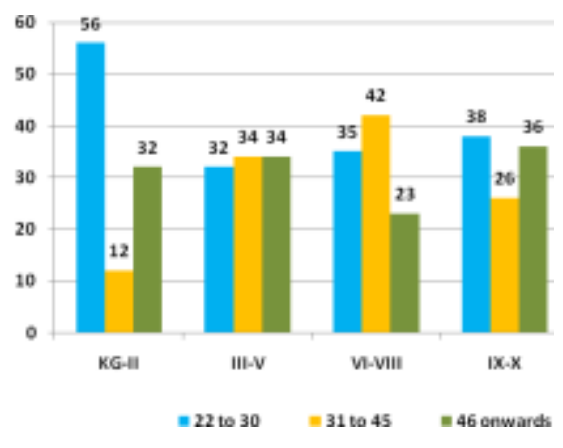

Figure 4. Influence of Age of Teacher

\section{Disciplinary Strategies}

Management of disruptive behavior in classrooms includes adoption of appropriate strategies with reference to disciplinary procedures and behavior-intervention plans. Many activities act as rein forcers to teach desirable behavior. There are five identified categories of responses available for teaching desired behavior:

- The use of words

- Physical expressions

- Physical closeness

- Activities, and things used as rewards

- Positive feedback

\subsection{Positive classroom behavior.}

In order to create a conducive learning environment teacher should analyze their approach, clarifying their strategies to make it easier to guide the class confidently and effectively. They should visualize possible challenges, imagine possible classroom challenges and review adequate strategies for dealing with them to enable to keep grounded when these challenges arise. It is expected that teacher make their expectations clear from the beginning. The rules to be followed in classroom should be positive, specific and concise and the consequences should be spelt if students do not meet expectations [11]. While encouraging good students teacher should praise mediocre students who are taking efforts for improvement as they often lack confidence and need more positive reinforcement [8]. It is the duty of a teacher to show Respect for the students including patiently listening to their needs and preserving their dignity. Consistent behavior helps as changing or shifting strategies show a lack of decisiveness when misbehavior occurs. Keeping students occupied is one way to handle behavioral problem as busy students are far less likely to exhibit disruptive behavior [4]. The students should work at appropriate levels; boredom and frustration often lead to students' acting out[10].

\section{Punishment}

Punishment is the most controversial aversive behavior management procedure, which has been widely used in past in Indian schools. This act include abuse, the use of punishment as a behavioral change procedure raise a number of concerns regarding legal and ethical ramifications. Punishment is proved effective in suppressing unacceptable behavior in classrooms but the reduction in disruptive behavior may not be pervasive across all settings [3].

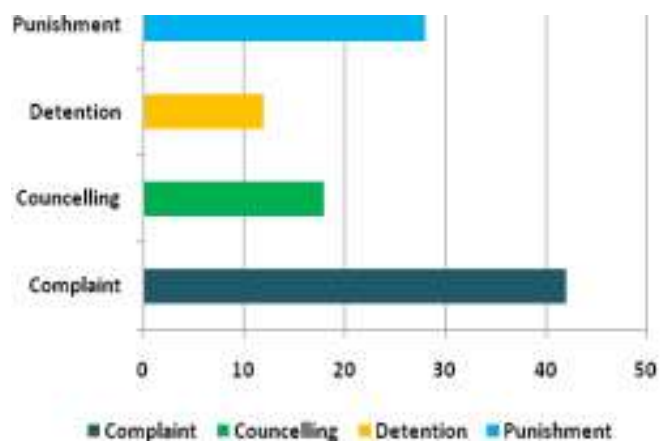

Figure 5. Preferences of Teachers for Disciplinary Actions

It has been found that its effect is not generally persistent over an extended period of time, in addition there is a possibility that the student may not acquire skills that replace the disruptive behavior .The use of punishment as a behavior reduction technique is an individual's decision (Figure 5 shows preferences of teachers for disciplinary actions). Many academicians suggest that punishment-based interventions should be eliminated, whereas others favor punishment as an important and effective method of behavior-control procedures [20]. The use of punishers inhibit, reduce, or control the future occurrence of an unacceptable behavior, the effects of punishers are limited. It will not teach desirable behavior or reduce the desire of misbehavior; currently used punishers by classroom teachers include factors as below: 
- Response cost

- Time out

- Overcorrection

- Contingent exercise

- Aversive conditioning

When students are not responsive to rewardbased interventions or praise/ignore strategies they can be punished. It is important that punishment should be combined with positive procedures and used discriminately, rather than routinely. It should be only in response to repeated misbehavior for students who persist in the same kinds of misbehavior and should be employed consciously and deliberately as a part of a planned response to repeated misbehavior [9]. It should be used only as a treatment of last resort and only after taking appropriate steps to ensure that the due process rights of students will not be violated and that the procedures will not cause psychological or emotional harm to the student [8].

\section{Classroom Design}

Classrooms are not only constructed spaces they are rather built environments that convey potent messages about how to think and act within a particular milieu. Classroom space shapes the behavior of instructors and students. The material context is very important as it affect the social patterning and learning processes which take place within a classroom. Student's behavior and learning process depend on the environment created within the space. The environment should cue appropriate behavior, provide stimulation, reduce ambiguity, and support and promote the intended activities, which can be achieved with the correct design. Size shape location of classroom in addition to other parameters like color in the environment also affects mood, satisfaction, motivation, and performance. A great deal of research has evaluated the emotional impact of color. As per research color affects arousal and fatigue levels which, in turn, influence mood. The color pink, has been found to decrease aggressiveness and have a tranquilizing effect, reducing maladaptive behavior. Furnishings, spatial arrangements and lighting can contribute to a design that aids in adapting student's needs. Good spatial design in a classroom includes air quality, materials availability, space, crowding, noise, result in increased teacher student morale and energy. Joyful atmospheres can be produced where students engage in deep thinking, test ideas, engage in problem solving and construct knowledge, rather than engaged in anti social behavior. In such environments students have lower levels of anti social behavior, and higher levels of schoolwork anxiety.
Many studies over the past ten years have looked at classroom size and classroom density and their impacts on student's behavior. It has been noticed that high density conditions have been found to lead to increased aggression, decreased social interaction, and non-involvement. Student's attitudes, voluntary participation and achievement all increase in smaller relative to larger classrooms. In classrooms with less students, teachers can have more interactions with each student, can provide a rich and vastly differing array of interactions, can establish learning centers, student learning teams, peer tutors and other instructional strategies, all of which improves the quality of interactions with each student. These effects may in turn lead to reduced problem behavior and increased educational performance.

\section{Summary and Discussion}

There are multiple determinants of antisocial behavior amongst students. However, the classroom environment and teacher's role appears to be a major factor for behavioral pattern of students. A coercive and punitive environment and inconsistencies in rule setting and applying consequences sometimes result in problem behavior. In addition other factors include low involvement and integration in school and a lack of appropriate parenting skills, antisocial networks affect student's performance. Three major factors within schools were identified that appear to promote a context in which punishment and extinction conditions are likely to occur which include a lack of clarity of both rules and policies; weak or inconsistent staff support and administrative follow-through; and few or no allowances made for individual differences. The resultant specific occurrences of punishment and extinction (e.g., disapproving comments, academic task errors, and a lack of recognition for either student or staff effort) appear to serve as setting events that evoke aggression, attendance problems (escape), and other antisocial behaviors. It appears, then, that a punitive school discipline environment is a major factor contributing to antisocial behavior problems.

Teachers' interactions with students affect students' behavioral and emotional engagement in the classroom.

Teachers' involvement with individual students had the most powerful impact on children's perceptions of the teacher. It also depends on the age and personality traits of the teacher. The affection, attunement, dedication of resources, and dependability expressed by the teacher shape the extent to which children feel that their needs are met, not only for relatedness but also for competence and self-determination. When teachers are less involved with students, students not only miss the involvement but also experience teachers as less consistent and more coercive. Generally young 
teachers convey enthusiasm and/or rapport and thereby elicit student interest and participation. This is refereed as charismatic behaviors which include speaking expressively, relating material to students' interests, and use of movement and gesture. There is a need for conceptualization of how teachers' and students' cognitions and knowledge mediate effective teaching. Subject matter content and teacher and student knowledge are to be focused on as important dimensions.

\section{Conclusion}

Classroom is a work place where positive teacher-student interactions modify classroom environment and improve student behavior. There is a deep rooted association between positive interactions with teachers which increases students' social skills, emotional regulation, motivation, engagement, cooperation with classroom rules and academic performance. A good teacher should have

- Knowledge of curriculum and pedagogy

- Knowledge and student friendly beliefs about managing student behavior,

- Student-focused views of instruction,

- Ability to carefully reflect on students' learning.

Teachers must be able to adapt strategies to meet students' needs, and have ability to organize instruction, create a well-managed and supportive environment for instruction, carry out cohesive instruction and be professional and reflect on student learning and instruction. They should adopt specific strategies or content to teach high risk students and struggling learners. They must be very aware of the student's understanding [of content] and present things more systematically. The students need things broken down. The teachers need to be willing to make adjustments, take longer, try new things. Teachers have to be tuned in to what is going on with the children. Sometimes they have to restructure their activities based on the students' needs. Their instruction has to be explicit, and content should be relevant and interesting to students. They should articulate why they were teaching a particular concept or strategy and develop instruction that was clear and engaging.

Teachers show the warmth, respect, and sensitivity they feel for their students through small gestures, such as welcoming students by name as they enter the class each day, calling or sending positive notes home to acknowledge good behavior, and learning about their students' interests, families, and accomplishments outside of school. Teachers also can help students develop peer friendships by having them work together, thereby learning to share materials, follow directions, be polite, listen, show empathy, and work out disagreements. Fostering students' social and emotional development can improve their interactions and attitudes toward school, thereby reducing problem behaviors.

\section{References}

[1] Alberto, P. A., \& Troutman, A. C. (1995). Applied behavior analysis for teachers. (4th ed.). Englewood Cliffs, NJ: Prentice-Hall.

[2] Ayers, B., \& Meyer, L. H., (1992) Helping teachers manage the inclusive classroom: Staff development and teaming star among management strategies. The School Administrator, 49(2), 30-37.

[3] Braaten, S., Simpson, R., Rosell, J., \& Reilly, T. (1988). Using punishment with exceptional children: A dilemma for educators. TEACHING Exceptional Children, 20(2), 79-81.

[4] Carpenter, S. L., \& McKee-Higgins, E., (1995) , Behavior management in inclusive classrooms. Remedial and Special Education, 17(4), 195-203.

[5] Charles, C.M., (2000) The Synergetic Classroom: Joyful Teaching and Gentle Discipline. New York: Longman.

[6] Edwards, Clifford H., (1997) Classroom Management and Discipline, 3rd Edition. New York: John Wiley and Sons.

[7] DiGuilio, (2000) Robert. Positive Classroom Management, 2nd Edition. Thousand Oaks, CA, Corwin Press.

[8] Dunlap, G., Kern, L., dePerczel, M., Clarke, S., Wilson, D., Childs, K. E., White, R., \& Falk, G. D. , (1993), Functional analysis of classroom variables for students with emotional and behavioral disorders. Behavioral Disorders, 18(4), 275-291.

[9] Kounin, J. S. (1970). Discipline and group management in classrooms. New York: Holt, Rinehart \& Winston

[10] Larrivee, B., (1992) Strategies for effective classroom management: Creating a collaborative climate (Leader's Guide to Facilitate Learning Experiences). Boston: Allyn \& Bacon.

[11] Madsen, C. H., Jr., \& Madsen C. K., (1983), Teaching/discipline: A positive approach for educational development (3rd ed.). Raleigh, NC: Contemporary Publishing Company.

[12] MacKenzie, Robert J., (1996), Setting Limits in the Classroom: How to Move beyond the Classroom Dance of Discipline. Rocklin, CA: Prima Publishing.

[13] Meyer, L. H., \& Henry, L. A., (1993) Cooperative classroom management: Student needs and fairness in the regular classroom. In J. Putnam (Ed.), Cooperative 
learning and strategies for inclusion: Celebrating diversity in the classroom (pp. 93-121). Baltimore: Paul H. Brookes.

[14] Nelson, J. R., Smith, D. J., Young, R. K., \& Dodd, J. M., (1991), A review of self-management outcome research conducted with students who exhibit behavioral disorders. Behavioral Disorders, 16(13), 169-179.

[15] Prater, M. E., Joy, R., Chilman, B., Temple, J., \& Miller, S. R.,( 1991), Self-monitoring of on-task behavior by adolescents with learning disabilities. Learning Disability Quarterly, 14(13), 164-177.

[16] Rosenbaum, M. S., \& Drabman, R. S. (1979). Selfcontrol training in the classroom: A review and critique. Journal of Applied Behavior Analysis, 12(3), 467-485.

[17] Schloss, P. J., \& Smith, M. A., (1994), Applied behavior analysis in the classroom. Boston: Allyn \& Bacon.

[18] Weiner, B. (1990). History of motivational research in education. Journal of Educational Psychology, 82, 616622.

[19] Weisz, J. R., \& Cameron, A. M. (1985). Individual differences in the student's sense of control. In C. Ames \& R. E. Ames (Eds.), Research on motivation in education: Vol. 2. The classroom milieu (pp. 93-140). San Diego, CA: Academic Press.

[20] Yell, M. L., (1990), The use of corporal punishment, suspension, expulsion, and timeout with behaviorally disordered students in public schools: Legal considerations. Behavioral Disorders, 15(2), 100-109. 